\title{
Mental Well-being of Albanian and Kosovo Albanian Immigrants
}

\author{
Voltisa Thartori ${ }^{1}$ and Nik A. Hisham Ismail \\ International Islamic University Malaysia, Kuala Lumpur, Malaysia
}

\begin{abstract}
Moving to a new country causes significant challenges for immigrants. Various reasons contributed to immigrants' mental well-being, such as language barriers, lack of family and social support, discrimination, and others that affect well-being and quality of life among immigrants in the host country. This qualitative study explored the lived experiences of 18 Albanian and Kosovo-Albanian immigrants residing in Malaysia. The objectives of this study are as follows: (i) to investigate perceptions of immigrants toward mental well-being; (ii) to explore coping strategies for mental well-being among immigrants; and (iii) to identify suggestions and recommendations of immigrants residing in Malaysia and Australia. Social Learning Theory (SLT) guided this study. SLT focuses on learning through observation and reflection. Therefore, this theory is suitable for the current study since our thoughts, actions and behaviours are influenced by social and cultural factors. This study employed a qualitative phenomenological case study using in-depth semi-structured interviews. The result showed that mental well-being was perceived as physical, mental and spiritual health; accomplishment and life purposes; and contentedness positively affected the immigrants' mental well-being. The immigrants resorted to several strategies in coping with mental well-being, such as calmness and having a positive attitude in solving their problems. The findings also recommended immigrants embrace a new culture and adapting their life in their host country.
\end{abstract}

KEYWORDS: Albanians and Kosovo Albanians, Coping Strategies, Immigrants, Mental Well-being.

According to the literature review, immigrants live abroad and stay abroad for various reasons: economic, political, social, cultural, etc. Immigration is not a modern phenomenon; it has existed throughout human history, and it has been characterised as one of the oldest social phenomena since the beginning of humanity. For thousands of years, people have left and are leaving their homes searching for better economic jobs, opportunities, and a better living climate for themselves and their families. Globalisation is the rapid movement of individuals, ideas, skills, money, products, and services across national boundaries. Economic globalisation has given global migration a new twist, triggering global uprooting and human movement. Since economic globalisation exacerbates national inequality, many people see migration as a requirement to improve their financial situation rather than a preference (Čiarnienè \& Kumpikaite, 2008).

Similarly, Albanian immigrants were pushed to leave their countries for economic, political and social reasons, Albania's case since the end of the communist era in 1990, and in Kosovo Albanians after the war in 1998.

According to the World Migration Report (2018), the total number of international migrants has increased over the past 50 years. In 2019, the estimated number of migrants was

\footnotetext{
${ }^{1}$ Corresponding Author E-mail: voltisat@gmail.com
} 
272 million people residing outside their birth countries. This is 119 million more migrants when compared to the 1990 consensus of 153 million and the 1970 consensus of 84 million. The percentage of immigrants has increased worldwide, which includes Albanians. It is reported that in 1990, 1 in 4 people from the Republic of Albania migrated across the globe (Kasimati et al., 2009).

Individuals relocate for progress and to have a good quality of life, to achieve their goals and dreams that are otherwise unattainable in their own countries. Individuals that follow this path fall under the definition of immigrants who plan their move before they arrive in the host country and are psychologically or mentally ready for the step. At the same time, refugees flee for their lives unexpectedly to known or unknown destinations, leading to impaired mental well-being and cause psychological health problems (Kaliska \& Akbey, 2019; Tribe, 2002). Immigration is not just a change of environment; it involves several other social, ecological, cultural, and behavioural changes, which causes various distressing situations that can lead to detrimental impacts on the immigrants' mental well-being (Al-Hawdrawi, 2017; Walter \& Siwar, 2021). Furthermore, immigrants face significant economic and social effects and psychological ones as a result of their relocation. Migration may entail a higher-paying career, the loss of old and the formation of new social links, as well as the psychological costs of missing one's homeland (Kahanec \& Zimmermann, 2008).

\section{Mental Well-being}

Many scholars consider well-being a complicated term because it is subjective, which means there is not only one definition. Instead, there are several definitions due to the variability of such descriptions. Since well-being has been viewed as a complex notion, contemporary research on well-being are classified into two dominant views: Firstly, the hedonistic viewpoint focuses on contentment, pleasure and happiness. This view focuses on the realisation and fulfilment of needs and the avoidance of pain and discomfort; in other words, increasing and maximising enjoyment and decreasing or avoiding pain. Secondly, the eudemonic viewpoint signifies self-realisation or self-awareness, which outlines well-being in individual function (Ryan \& Deci, 2001).

Additionally, Diener (1984) asserts that psychological well-being represents how individuals assess their lives in terms of the cognitive appraisal on life's satisfaction or affective assessments such as a hedonistic evaluation of well-being in terms of feelings and emotions. Diener suggests that people can assess and evaluate their lives subjectively regarding right or wrong, good or bad, and negative or positive. He reported that psychological well-being could positively and negatively impact mental health (Diener, 1984). Furthermore, Bradburn (1969) defines well-being as an individual's psychological reactions when facing difficulties and coping strategies. His research examines the differences between negative and positive impacts on an individual's everyday life. The results showed that individuals experienced a higher level of psychological well-being when there were positive impacts; likewise, a low level of wellbeing is characteristic of adverse effects.

Balidemaj \& Small (2018) conducted a study on 139 Albanian-American immigrants age 21-35 years old that examine the correlation between Acculturation, ethnic identity, and psychological well-being. Moreover, the outcomes demonstrated that Acculturation, ethnic identity and psychological well-being were positively correlated. The results indicated that ethnic identity and Acculturation affected Albanian's psychological well-being in the USA.

Another study conducted on Acculturation on 306 Albanian immigrants living in Greece explored the effect of demographic variables on Acculturation. The outcomes demonstrated in terms of gender females positively affects the integration of immigrants. Regarding immigrants' older age, they led them to separation, whereas the extended stay in the host country led to Assimilation. In parallel, the second generation of immigrants enjoyed extra 
Assimilation and much less alienation and marginalization than the first generation. The newcomers in middle age face challenges to incorporate and integrated into Greece society and face separation. An immigrant who resides relatively at a younger age or was born in Greece enjoys and experiences extra Assimilation (Papadopoulos et al., 2015).

A study examines the lived experiences and perceived reasons for loneliness on older migrants' social well-being. The researcher used qualitative study in-depth interviews on Albanian and Moroccan migrants of the zero and first generations aged and older residing in the Marche region of Italy. The results indicated that the immigrants surrounded by their family circle had a sense of contentment with their contact and relatives; this shields them from social isolation, not loneliness. Although they rarely express this to their circle of family and relatives. The participants experienced feelings of loneliness. The cause of their loneliness mainly relates to deficiency of friend's relationships-having a conversation, remembering the good old times, interacting with others when their family are busy, discussing the intimate matters that were not able to share with family members. Socializing with people outside of the family circle, mainly with co-ethnic peers, may reduce loneliness feelings. However, factors consisting of discrimination and not speaking the Italian language, lots of free time, lack of financial resources contributes to feeling loneliness (Cela \& Fokkema, 2017)

\section{Theoretical Framework of the Study}

The theory that guided this study was social learning theory developed and formulated by Canadian Albert Bandura (1969). This theory emphasises the importance of modelling and reflecting on others' actions, attitudes, and emotional responses. Social Learning Theory (SLT) focuses on learning through observation and reflection. SLT describes how the environment around us and cognitive and exploratory factors influence human beings' learning and behaviour. SLT proposes three factors: Personal, environmental and behavioural, and all three aspects regularly interact and influence one another. An individual behaves based on the information they have learned or observed. Social and ecological factors are enhanced when individuals can fulfil their personal and social goals and achieve a sense of purpose in society by building strong and positive relationships with others and contributing to their community. Accordingly, these three factors: personal, environmental and behavioural, are co-operating and continuously influence one another (Bandura, 1969). Therefore, this theory is suitable for the current study since our thoughts, actions and behaviours are influenced by social and cultural factors. This results in forming good mental well-being when facing psychological health problems.

\section{Figure 1}

The Conceptual Framework of the Study
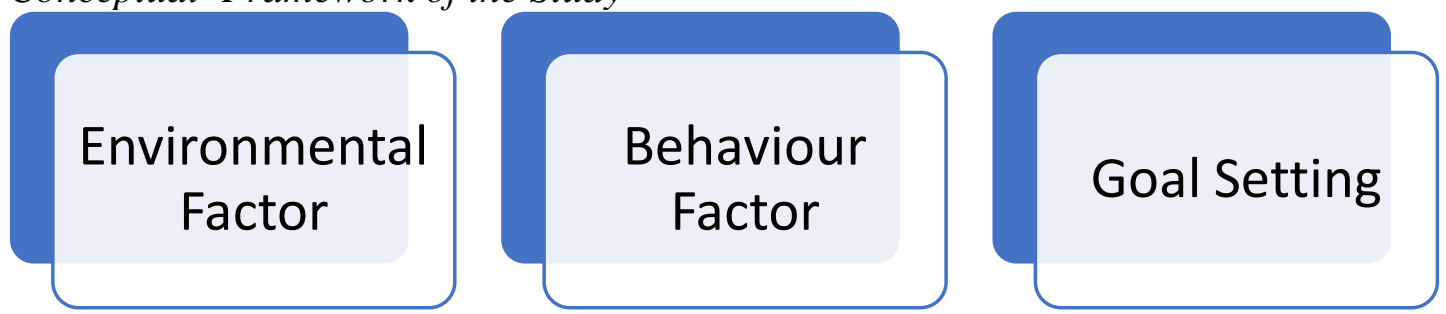

Based on the SLT theory and literature review discussed, the researchers formulated the following dimensions as a conceptual framework for the study, see figure 1. The study examines the behaviour factor, environmental factors, and goal setting. The constructs, namely, behaviour and environmental factor, will be taken from this theory to be used in this study. Factors such as goal setting have been adopted from the literature review. To summarise, the dimensions used as a conceptual framework for this study are shown below. 


\section{Methodology}

The primary purpose of this qualitative, phenomenological case study was to investigate and explore, in their own words, the experiences of Albanian diaspora immigrants living in Malaysia. Data analysis focused on three pre-determined research questions:

RQ1. What are immigrants' perceptions toward mental well-being?

RQ2. What are the strategies immigrants use to cope with mental well-being?

RQ3. What are the suggestions and recommendations of immigrants residing in Malaysia and Australia?

This study used a qualitative phenomenological case study. This phenomenological approach, paired with the case study method, allows the researcher to comprehend and elaborate the phenomenon and human experiences or "the essence and the underlying structure of a phenomenon" (Merriam, 2009, p. 23)

A phenomenological perspective aids the comprehension of the essence of a person's experience, focusing on gaining a rich understanding of a specific encounter from the participant(s). The participants' personal, first-hand information provides descriptive data that the researcher can use to strengthen the understanding of the "lived experience for a specific event" (Patton, 2002, p. 104). This phenomenological approach, paired with the case study method, allows the researcher to comprehend or understand elaborate human experiences and "the essence and the underlying structure of a phenomenon" (Merriam, 2009, p. 23).

Phenomenology is one of the many varieties of qualitative research that prospered during the philosophical development of the early 20th century. There are divisions within the field regarding the techniques and characteristics via which phenomenology defines itself. The two principal branches are: 'descriptive phenomenology', intending to find and describe the meaning of people's stories and their experiences, and 'interpretive phenomenology' (or hermeneutics), aiming at deciphering the importance of people's descriptions (Pringle et al. 2011).

Husserl (2004) asserts that obtaining subjective qualitative comprehension is a precursor to accomplishing the objective quantitative skill. A phenomenological approach does not focus on the individuals themselves, but their everyday lived experiences (Creswell, 2007)

Data was collected using a one-to-one in-depth semi-structured interviews method to get rich information from the participants to understand better mental well-being among Albanian diaspora immigrants living in Malaysia and Australia. The one-to-one interview is a better method of understanding people's perceptions, believes, understandings of their experiences of the phenomenon. Additionally, in-depth interviews promote sympathy and compassion and give the researchers an empirical basis describing people perceptions, although also logically reporting their feelings, views and insights as part of the data (Patton, 1990).

\section{Sampling}

The participants selected for this study will conform to the following criteria: (a) they must be from the Republic of Albania and Kosovo, (b) they must be currently living in Malaysia and Australia c), residing in Malaysia and Australia for at least five years, and, d) they must be 18 years old and above. Purposive sampling was used in this study to recruit participants. According to Cooper and Schindler (2003), purposive sampling allows the researcher to choose participants based on their unique characteristics, experiences, attitudes, or perceptions. 
Table 1

Respondents Biographic Profile

\begin{tabular}{|c|c|c|c|c|c|c|}
\hline Participant & Age & Gender & Education & $\begin{array}{c}\text { Employment } \\
\text { Status } \\
\end{array}$ & $\begin{array}{l}\text { Marital } \\
\text { Status }\end{array}$ & $\begin{array}{l}\text { Years in } \\
\text { Malaysia }\end{array}$ \\
\hline 1 & 35 & Male & Doctorate & $\begin{array}{c}\text { Global Account } \\
\text { Manager }\end{array}$ & Single & 14 \\
\hline 2 & 30 & Female & Master's & Accountant & Married & 8 \\
\hline 3 & 39 & Female & Bachelor's & Housewife & Married & 21 \\
\hline 4 & 40 & Female & Master's & Researcher & Divorced & 22 \\
\hline 5 & 47 & Male & Master's & Business Owner & Married & 22 \\
\hline 6 & 36 & Male & Doctorate & $\begin{array}{l}\text { Financial } \\
\text { Advisory }\end{array}$ & Married & 14 \\
\hline 7 & 32 & Male & Master's & $\begin{array}{l}\text { Administrative } \\
\text { Manager }\end{array}$ & Married & 11 \\
\hline 8 & 30 & Male & Master's & $\begin{array}{l}\text { Cloud Solution } \\
\text { Architect }\end{array}$ & Single & 10 \\
\hline 9 & - & Male & Doctorate & $\begin{array}{l}\text { University } \\
\text { Professor }\end{array}$ & Married & 5 \\
\hline 10 & 47 & Male & $\begin{array}{l}\text { Some } \\
\text { Diploma }\end{array}$ & Self-Employee & Divorced & 27 \\
\hline 11 & 19 & Female & $\begin{array}{c}\text { High } \\
\text { School } \\
\text { Diploma }\end{array}$ & Student & Single & $\begin{array}{l}\text { Born in } \\
\text { Malaysia }\end{array}$ \\
\hline 12 & 41 & Female & Master's & Business Owner & Married & 18 \\
\hline 13 & 22 & Female & Bachelor's & $\begin{array}{c}\text { Student/English } \\
\text { Tutor }\end{array}$ & Single & 5 \\
\hline 14 & 30 & Female & Master's & Architect & Married & 10 \\
\hline 15 & 33 & Female & Master's & $\begin{array}{c}\text { Professional } \\
\text { Secretary }\end{array}$ & Married & 8 \\
\hline 16 & 47 & Male & Bachelor's & Business Owner & Married & 18 \\
\hline
\end{tabular}

\section{Data Analysis}

This study utilised a thematic analysis because there is growing support for claiming that thematic analysis is one of the most used methods in analysing qualitative data sets. Proper qualitative research is used to provide interpretations and explanations based on data collection. Factors that affect any issue experienced by the respondents of the study can be discovered through thematic analyses. The experiences and explanations should not be undervalued to understand the individual's behaviours, patterns, and thoughts. A phenomenon can be better understood through thematic analyses (Bryman, 2012).

Furthermore, Braun and Clarke (2006) claim that thematic analyses should be a foundational qualitative data analysis approach. They argue that thematic analysis is a technique that can be used throughout various epistemologies and phenomena. It is a technique for "identifying, analysing, organising, describing", and reporting themes within a data set (Braun \& Clarke, 2006). Thematic analysis is a method that helps organise the findings of the study (Pope et al., 2007). The first stage in the analysis is the coding aspect by collecting and reviewing the raw data set. The second stage is to find themes and sub-themes from the data set. The researcher must be familiarised with the transcript when obtaining the themes. (Bryman, 2008). Furthermore, the researcher reads all the transcriptions repeatedly to be 
familiar with the transcribed data and more comfortable analysing the data (Ahmad, 2017). The themes that emerged were compared and described with another source of data.

\section{Combining Main Ideas in Generating Themes}

As stated by Creswell, the most fundamental factor of the research is to answer the research question. The question then arises how themes should be generated in the qualitative study, which requires a critical mind to analyse the data from the main ideas and narrow them down to several themes. A table was used to generate the themes that explained the central phenomenon in the research. The table combines all the main ideas to generate the themes. The table can have columns depending on the participants of the study. In this research, 18 informants participated. The main ideas from each participant were listed and interpreted to generate and endorse the themes. There might be ideas that reflect a single theme or several themes and concepts similar, or appear to be so, are assigned to a particular colour, which aids the themes' systematic endorsement (Ahmad, 2017).

\section{Findings}

Research Questions 1: What are the perceptions of immigrants toward mental wellbeing? The findings are categorized into three main themes:
A) Physical, mental and spiritual health,
B) Accomplishment and life purposes, and
C) Contentedness.

\section{A) Physical, Mental and Spiritual Health}

All the participants were able to provide their understanding of what they perceived of mental well-being. Several respondents claimed mental well-being is being in a state of good health mentally, physically and spiritually. The informants perceived mental well-being as taking care of mental, physical and spiritual aspects. They believed that it is easier to balance their lives if an individual feels good mentally, physically and spiritually. Life can easily be managed when all these components are integrated and harmonizing each other: The following responses from the informants reflecting on mental well-being:

\section{Well-being to me.... to everybody, I guess it's the state of being very well in terms of mental in terms of spiritual in terms of physical situations.} (Respondent 14)

....to me being well with your health, body, mentally and spiritually? That's mental well-being. (Respondent 15)

Other previous studies (Shah, 2005) support this finding and provide the definition of good health as including not only the body and mind but also spirit; this is called the "holistic view of health". A holistic view of health is a state of homeostasis between the mind, body and the spiritual aspects. An imbalance of these aspects will result in discomfort and therefore, spirituality plays a significant role in the balancing of every aspect of life.

According to the WHO, health has been categorised into three components: mental, physical and social, while ignoring the spiritual aspect. The most quoted definition of health by the WHO (1948) is, "A state of complete physical, mental and social wellbeing, not merely the absence of disease or infirmity" (p. 187). Undoubtedly, it appears that people strive to attain 
physical, mental and social wellbeing, but this is not sufficient as there is another factor such as spirituality that needs to be considered too.

\title{
B) Accomplishment and Life Purposes
}

The fifth theme that emerged for the first research question is "Accomplishment and Life Purposes". Fyodor Dostoyevsky, a Russian writer, once said that "The mystery of human existence lies not in just staying alive, but in finding something to live for". (Fyodor, 1912, p. 268). Everybody and everyone has a purpose in life, and that purpose differs from person to person. Some people will say this purpose is to enjoy life, to live happily and become the best version of themselves. Some may say that the meaning of life is to follow God's will whilst others will say achieving goals with various people; undeniably, there are multiple views for this.

The typical responses of the interviewees on how they perceive mental well-being were having a purpose in life and achieving goals, whereby approximately $45 \%$ of respondents stated this. The fulfilment of life purposes, such as living life fully and being responsible for family and society. Furthermore, the respondent also explained that having good mental well-being is like having the right mindset towards life. A good stand may help a person grow and feel happier towards anything a person wants to achieve. Some respondents believed that life without goals means nothing; having no goals and no motivation to accomplish these goals makes life meaningless and worthless, describing their mental well-being.

Yeah, of course, of course, without goals in life, there is no life. So, you set these goals and work towards your goals and achieve them. That's how mental well-being is. (Respondent 7)

\begin{abstract}
At a personal level, mental well-being means to achieve my goals and success in life. In life, we have goals and purpose. We all do. I believe goals are the main factor to have a happy life because our mind and energy is focusing until we reach there. (Respondent 16)
\end{abstract}

To sum up, based on the respondents' responses, they perceived mental well-being as having purposes and achieving life goals. Some participants highlighted that having no goals and life purpose leads to meaningless and worthless life. Therefore, life purpose contributes to a happy life and self-development. Achieving a particular goal gives a sense of accomplishment and satisfaction. Goals and purpose in life can trigger motivations and enhancing mental wellbeing. Locke and Latham (2019) emphasised and developed the Goal-Setting Theory of Motivation (GTSM). The GTSM highlights the significant relationship between goals and performance. A goal is simply understood as a person's intentional knowledge of what to do. Locke and Latham propose that goals direct attention and action. Goals that are challenging, difficult, and require activity and energy to achieve them cause tremendous effort. Goals stimulate and mobilise people to develop plans which will allow them to perform at the specified level needed to accomplish the goal. In conclusion, accomplishing goals can result in motivation and satisfaction; however, if the goal is not achieved, this leads to lower motivation and frustration (Lunenburg, 2011). Therefore, having a sense of purpose in life contributes to positive experiences, such as happiness and well-being (Frisch, 1998).

A purpose can be thought of as self-organising one's life, classifying and arranging goals, managing behaviours and providing a sense of meaning for life. A purpose and a mission will guide life goals and daily decisions by controlling the use of an individual's resources. Moreover, a purpose offers a person "A self-sustaining source of meaning through goal pursuit 
and goal attainment" (McKnight \& Kashdan, 2009). Ryff (1989) created a psychological wellbeing model that includes six different components of positive mental functioning. These dimensions include aspects such as the ability of individuals to realise their positive attitudes and their unique talents. The dimensions of the model are as follows: 1. Self-acceptance, 2. Environmental mastery, 3. Purpose in life, 4. Positive relations with others, 5. Personal growth and 6. Autonomy (Ryff \& Keyes, 1995; Ryff \& Singer, 2008). Ryff describes a purpose in life as "the belief that one's life is purposeful and meaningful"; following from this definition, everyone has the sense that life has a purpose and is meaningful.

\section{C) Contentedness}

Contentment cannot be found through materialistic substances. Contentment is more than just having gratitude and being grateful for the little things in life; it is to be thankful for simply being. It comes from oneself, from being at peace with what a person has and understanding that it cannot have everything. The respondents perceived mental well-being as fulfilling one's happiness. Happiness is not just being happy with what you have but also being thankful for what God has given you. That is contentment in life, to enjoy, to appreciate, and to show gratitude toward living. "Well, definitions of happiness for me is that if I am happy with what I have that's... so I will be happy will what I have been given to me by God." (Respondents 5); and,

Happiness to me is being happy with what you have, what God, Allah has already given to you not waiting or dreaming for something that you don't have it....happiness is to be satisfied with what you have.

\section{(Respondents 15)}

Furthermore, the respondents explained happiness is the satisfaction of whatever you have and the appreciation of your belonging and possessions. The other respondents described happiness as being grateful for the things that you have done, being thankful with life overall, and identifying your abilities and capabilities to what you want to achieve in this life.

Okay.... mental well-being to me is being happy with whatever you have, being comfortable with life and the things that surround you. (Respondents 16)

I have this philosophy of being happy for what you have and to be happy for what you will have. (Respondents 14)

The results show that the informants are contented and grateful for whatever they have achieved in their lives and with whatever God has given them. Contentment is a state of satisfaction and acceptance with life. To have contentment is to have "days without special pains, without special cares, without particular worry, without despair; days when calmly wonder, objective and fearless" (Hesse 26, 1961). Furthermore, according to psychology, contentment is one of the 'valued' psychological phenomena, alongside satisfaction, hope and optimism, and happiness and well-being (Coleman, 2015).

Research Question 2: What are the strategies immigrants use to cope with mental well-being?

The findings show three main themes: 

A) Calmness,
B) Rationalising the problems, and
C) Positive attitudes.

\section{A) Calmness}

Regardless of where you are from, where you live, your abilities, and your education level, life is filled with difficulties and obstacles. An individual must choose healthy and productive ways to react to these difficult situations. When we face problems in our lives, the first thing a person does is focus on finding a solution. Life is full of answers and solutions, and none is impossible to be resolved.

The respondents reported that being calm was one of the strategies they opted for in a stressful situation. Some respondents reiterated that being calm in a stressful situation helps them to see things through with clarity. Besides, the respondents admitted that the best way to solve any problems was to stay calm. With some understanding of the situation and utilizing logical thinking, they would solve their problems. Respondents also suggested that being calm with high consciousness in their state of mind could help make decisions with a clear mind.

...well, in a stressful situation....I will make sure to be calm and think logically about how to solve that problem. I will try to work on my situation rather than stress out. (Respondents 16)

I will try to come down.... calming myself.... I always ask a lot of questions to myself; you know to whatever stressful things happened. I tried to calm myself down; you know I use different techniques to do it.... (Respondents 1)

Calmness in terms of emotional control refers to how people learn to control their emotions; and to have a state of happiness and tranquillity, which is worthwhile having it. (Tissari, 2018)

\section{B) Rationalising the Problem}

Analysing the problem is another strategy used by immigrants to cope with mental wellbeing. It is not surprising that an individual will encounter some problems either in their personal life, family life, or working life as a person or as a foreigner. Under these circumstances or situations, sometimes a person needs to be rational and less emotional, especially for immigrants away in the host country. There are many ways of overcoming or solving problems. The familiar way among the immigrants will be utilizing their rational abilities such as identifying, analysing, and then trying to solve the issues.

In a stressful situation, several respondents expressed that they would focus on rationally identifying, analysing, and finding a solution to their problems. The respondents reported that all of the issues they encountered could be rationally solved by chunking the problems to identify reasons, measure the problems' magnitude, and solve problems with several options.

Best processes $I$ think is trying to rationalise things, trying to understand how things came into being why they are in such a state of affairs. (Respondents 9) 
One is to accept that you have a problem ... is to study your problems, you know why where it came from? What was the reason? And then you know the reason why it happened. (Respondents 14)

It take some time to think about my stressful situation. I mean, we should communicate with ourselves the stress, for example, asking what kind of problem is this? Why this problem came in first hand? What can what, what can I do to solve this problem. (Respondents 16)

From the research findings, it can be concluded that the immigrants utilised many approaches to analysing problems that align with previous study approaches. The first approach was to focus on the problem rather than the stress that arises from the problem. Another method was to reason and to solve the issues. In the literature, the most used approach of problemsolving techniques among the immigrants was to define, measure, analyse, improve and control (DMAIC). The DMAIC model shows all the significant and critical criteria to solve a problem, initially defining the problem, then analysing how the problem arose, and finally, controlling it (Dale et al., 2007). The DMAIC model signifies how to address a problem by assembling quality instruments while creating a consistent and regular routine in solving issues (Bezerra et al., 2010). All these approaches help to determine the origin or the root cause of the problem or the issue.

\section{C) Positive Attitude}

A famous saying articulates that a positive attitude can help you achieve success. The underlying values of the expression propose that success is not just measured through abilities, capabilities or having the best skills because an individual will not get very far if they have a bad attitude. A positive attitude is, therefore, beneficial in all aspects of life. A positive attitude harbours success and helps to create and maintain healthy mental well-being. A positive attitude leads to positive results, and it makes life more honest and pleasurable. Thinking big and positive is a habit of success. With a positive mindset, a person can positively face the world and its challenges, and they can solve difficulties efficiently and wisely. The interviewees stated that they have a positive outlook on life. They could see that their goals and having prosperous life could accept life as it is, no matter what situation they are in. Whether the situation is bad or good, they exhibited optimistic beliefs and attitudes for today and tomorrow.

Additionally, some participants stressed that a positive attitude or positive mindset was a coping mechanism to overcome their difficulties or a bad situation. The informants in this study felt that they have a positive mindset towards achieving their goals and purpose in life and dealing with their difficulties. Several respondents expressed that they have a positive attitude and a positive mindset to overcome their challenges and problems.

The best approaches to deal with difficulties in life are firstly having a positive attitude and mindset toward the problems and seeing the situation in a different perspective. (Respondents 2)

Well, I do actually.... I usually look for a positive way and try to solve the problem positively...I don't look at the problems.... as problems... I mean, I always look out for solutions... and solve the problems... (Respondents 10)

Positive thinking is a mental state that acknowledges growth, development and success. It is a mental attitude that anticipates positive accomplishments and results in an individual 
being more motivated and believing that they can achieve anything and everything. A positive mindset experiences contentment, pleasure, joyfulness, good well-being and the fruitful results of every condition, setting and action. The true meaning of positive thinking is to approach life's barriers and difficulties with a positive outlook. It does not necessarily mean avoiding problems, but rather, it is a positive perception and making the most of any problematic situation. To see the best in other people and oneself is part and parcel of a positive outlook or positive attitude (Wang et al., 2012).

Research Question 3: What are the suggestions and recommendations of immigrants who are residing in Malaysia?

Three themes were emerging:

A) Adapting to the Malaysian culture,

B) Opportunities, and

C) Freedom to practice Religion.

\section{A) Adapting to the Malaysian Culture}

Albanian and Kosovo Albanian immigrants who have lived between five to 25 years in Malaysia have begun to acculturate themselves into the host country's culture and have adopted some aspects of its multicultural society. Furthermore, the immigrants adopted and acculturated to the Malaysian culture. Kim (2006) asserts that acculturation is common among immigrants, and it is a process of cultural adoption of immigrants into the host society. The Albanians and Kosovo Albanians adopt the acculturation process and assimilate into a multicultural society like Malaysia in many aspects of their daily lives. Furthermore, the immigrants adopted and acculturated to the Malaysian culture. Acculturation is commonly defined as the cultural adoption of immigrants into society (Kim, 2006).

They began to understand to live in harmony, respect, and be mindful of Malaysian multiculturalism's sensitivities issues. For example, some respondents believed that accepting and adopting the host country's culture is the key to live their new life without deserting their own culture.

Accepting a new culture in one's life is a long process that takes time. Some respondents voiced their anxiety and worries, especially fear of losing their identity, yet other immigrants accept the new environment with open minds. Environmental psychology is a branch of science that analyses how human behaviour is affected and influenced by the environment, including social and learning information. According to the study (Bandura, 1969), environmental factors influenced the immigrants, as evidence by the informants. Some respondents reported that they became more open-minded after being exposed to different ethnic groups in Malaysia.

The immigrants learned to respect and not pre-judge people from different races, ethnicities, religions, languages and cultures that are part of Malaysian multicultural society. Harrison and Klein (2007) refer to cultural diversity as a function of social categories, such as the Malaysian multicultural society grown from common attributes from norms, values and traditions of a young nation. Indeed, as a nation of immigrants, Malaysians embraced these norms, values and lifestyles, which later become part of a new experience and alien to a new immigrant like Albania and Kosovo.

The immigrants also showed their gratitude and appreciation towards Malaysians, making them feel welcome and grow positively in a multicultural society that they had never experienced in Albania and Kosovo. They perceived that Malaysians, in general, are calm, patient and humble people, and Malaysians tend to have reasonable consideration and appreciate their life more even though they are different. The respondents believed that all the 
positive attitudes they encountered in Malaysia reflected their attitudes before migrating to Malaysia.

\begin{abstract}
Malaysian culture....is their humbleness and the soft attitude and the acceptance of others...so yeah, I think it has impacted me in that sense I have adopted it yes it has made me a calm person, much calmer person and maybe much less imposing in that sense. (Respondents 4)
\end{abstract}

\begin{abstract}
Yes.... It impacted me somehow when I was in Malaysia; I started to learn how to be patient, I should say. Patient and modest two things I love about Malaysians...they are very calm persons.... usually, we European are a bit sharp and loud and hot-tempered blood (laughing) they are calmer so, this positively affected me.... it's positive.
\end{abstract}

(Respondents 14)

Ultimately, the immigrants stated that many positive aspects came from being exposed to the Malaysian culture that has improved their attitudes towards life. For example, they have become calmer, like many Malaysians. According to Bandura's Social Learning Theory (Bandura, 1969), certain behaviours are learned in a social environment through observations. An individual learns and behaves based on information from the environment.

Furthermore, our behaviours are controlled by our thoughts and actions, which results in a change of behaviour. Our observations are influenced by how we process things internally and interpret things based on environmental factors. For example, Albanian immigrants observed how Malaysian people behave. According to the participants, Malaysian people have a softer and calmer personality that the Albanian immigrants learned from and emulated, resulting in a change in their behaviour. Albanian people were heavily influenced by how they lived their daily lives in Malaysia as behaviour is also affected by the environment. The environmental factor is an interdisciplinary method focused on the interactions between individuals and the environment. The environment is described as the surrounding condition that may directly influence a behaviour (Bell, 2001, as cited in Phua, 2010). Furthermore, the American Psychological Association (2016) suggests an interaction between two cultures can establish successful goals achieved by most Albanian immigrants living in Malaysia.

\title{
B) Opportunities
}

As mentioned throughout this research, many factors drive people to migrate and, often cited by literature, escape their country's conflicts and economic problems, get a better job, a better life, and better opportunity. Albanians migrate for better opportunities to improve their lives, a better quality of education, learn a new language, be exposed to better business opportunities, etc. According to the participants, Malaysia is a country with excellent opportunities. The participants reported that the main benefits that immigrants are given are opportunities in education and business prospects. For example, some respondents who had been staying for some time would recommend Malaysia to his fellows, Albanians planning to migrate. The participants believed that Malaysia has an excellent education system compared to other countries, including Albania and Kosovo. This includes some of the world ranking universities in Malaysia. The respondents perceived Malaysia as the land of opportunity in education, business, employment and better quality of life. The following responses from the informants reflect the concepts: 
I think they (Malaysians) are more advanced in terms of education.... their education system is better than ours even you see the ranking of the universities around the world they have a couple of universities which are like at the top in the world, which we don't have. (Respondent 1)

Those people who have left the country they probably have come for better opportunities for a better life, so I guess Malaysia as a country offers better education, I mean they are enjoying the same benefits as locals, they have the opportunity to send their kids, into local schools right; and I mean good business opportunities. (Respondent 3)

Additionally, some respondents also reported that immigrants in Malaysia are exposed to new languages such as English and local ethnic languages like Bahasa Melayu, Mandarin, and Tamil. In today's world, the chance of learning a new language is an excellent opportunity for achieving a better future and options in people's lives. Being an immigrant in Malaysia is an opportunity for the immigrant to learn main business languages like English and Mandarin. Working and integrating into Malaysian multicultural society helps the immigrants learn these languages, which are international languages and spoken throughout the world; therefore, knowing English and Mandarin will be very beneficial for the immigrants even if they had to leave Malaysia. Banarjee \& Verma (2009) and Bloch (2005) emphasise the importance of immigrants in pursuing education and upgrade their host countries' skills for better opportunities in the future.

\section{C) Freedom to Practice Religion}

During the communist regime, Albanians were prohibited from practising any form of religion and in 1967, Albania was declared the first atheist country in the world. After the downfall of communism, Albania's people were challenged with harsh realities like poverty, underdeveloped resources, unemployment, and health and socio-religious development. In socio-religious development, almost 90 per cent of Albanians considered themselves Muslim from the Ottoman Empire until the downfall of communism in 1990. However, during the communist regime, most Albanian Muslims were banned from practising Islamic teachings, and many mosques were converted into museums. The propaganda of atheism in Albania could be observed in many social activities, including the education system. Only after the end of communism, in 1990 people were free to practice their religion again.

The respondents found being able to reside in Malaysia as a golden opportunity to freely and openly practice their religious beliefs. The interviewees stated that they felt free to practise and adhere to Islamic teachings in Malaysia. Besides, they were convinced that Malaysia is a perfect country to live in as a Muslim. Islam in Malaysia is not perceived as a powerful way of life like in some other Muslim countries. Many respondents found that Islam is practice moderately here in Malaysia.

Some respondents expressed prejudices against females who wear hijab in schools and workplaces in Albania and Kosovo. However, they found in Malaysia that females were given a choice to choose whether to wear hijab or not freely, and society accepts them without prejudices and penalising their actions. The respondents also found Muslim-friendly amenities conveniently provided for Muslims in Malaysia, such as prayer halls, halal restaurants and stalls, and Islamic institutions like schools, higher education institutions, and hospitals. These are some examples of religious freedom that the immigrants appreciated while residing in Malaysia. For them, these religious infrastructures will make it easy for someone who wants to practice religion with freedom. 
Malaysia is a country that offers this...the freedom to practice your religion...especially Islam since in our country also populated by Muslims... for example (in Albania) if you are covered (hijab) you cannot go to school or... you cannot work in government. (Respondents 2)

The Muslims being like the majority in Malaysia. I think they got like freedom of practising their religion. For example, if you wear a hijab in Albania, they would like to look at you weirdly and ask you whether somebody forced you to wear a hijab. So, here (Malaysia) it's like you can wear it. You don't wear it is up to you. (Respondents 11)

Every human has the right to the basis of freedom. Freedom includes all aspects that include religion, political, justice, etc. (Madani, 2011). Freedom is a treasure that everyone is fighting to attain. Malaysia is one of the countries that exhibits a multiracial society with different cultures, races and religions, and has a harmonious co-existence between its citizens (Shah \& Sani Mohd, 2011). Albanians suffered during the communist era as there was no freedom of speech, freedom of choice, and no freedom in practising religion. Therefore, it is understood from the respondents' perspectives that Malaysia is a country that allows them to practise Islam with freedom.

\section{Discussions}

The findings of this study are expected to shed some light on how to improve and enhance the mental well-being and help-seeking behaviour of Albanian immigrants residing in Malaysia and Australia. Due to the complexity of Albanian culture and the aims of this study, the themes generated tended to be dynamic. The participants in this study displayed an excellent general understanding of mental well-being. All of them expressed the importance of having a purpose in life to achieve their goals, and accomplishment and life purpose leads to happiness. Islam guides Muslims to be honest, hopeful, just, truthful, faithful to their promises, and have a purpose in life and a positive outlook on life. However, all of these attributes are not easy to adhere to. The Qur'an states that patience and forgiveness are two conditions for entry into Paradise in the verses (Fușsilat: 34-35). Therefore, immigrants to balance their well-being. They incorporate calmness, prayer, positive attitude, happiness, gratitude, purpose, accomplishment, balanced life, self and life development, and social interaction, all of which contribute to their emotional growth and create a sense of belonging into the host country.

In dealing with the psychological problems that the immigrants faced, they used coping strategies such as calmness to deal with a stressful situation. Furthermore, immigrants have a positive attitude towards solving and analysing problems. The findings of this study are consistent with previous studies, particularly with (Wong 2002) conducted a qualitative survey of coping mechanisms among Chinese immigrants deals with psychosocial stressors encountered during the migration process. Immigrants used optimistic similarities to make their lives in Hong Kong seem more favourable, making it easier for them to accept their difficulties in the host country. For example, despite their disadvantages of insecure work and low wages, a young immigrant who compared his life before and after migration felt that he had more freedom and choice in Hong Kong. He was not regretting coming to Hong Kong. Therefore, having a positive attitude towards difficulties in life, there are more options in solving and analysing the problems. Kabir (2013) indicated that an 'attitude' is defined as the mental position that signifies a person's degree of like or dislike for things. Therefore, a positive attitude is commonly attributed to feeling optimistic and having a hopeful state of mind. An individual with a positive attitude tends to have a positive outlook on life; the informants stated that they 
looked to their life challenges positively rather than negatively. They saw their difficulties as temporary, which resulted in optimism.

Residing in a foreign country, an individual has to respect and accept diversity by interacting with the locals and accepting them as they are. Social interaction offers an individual the opportunity to blend in with the locals and assimilate into a foreign country. All these strategies enabled the immigrants to face challenges with a positive attitude. The findings of this study are consistent with Hemmasi and Downes (2013) and Hinsliff (2007). Adapting to a new culture and environment is crucial for migrant settlement, particularly for those who come from cultures that are considered to be distant. Al-Hawdrawi (2017) examined the effects of immigration on the mental wellbeing of middle eastern immigrants residing in the USA. The results showed that roughly half of the participants faced anxiety, depression and emotional concerns of undefined diagnosis, which can be attributed to them experiencing "social discrimination, health disparities, and poor acculturation". The anxiety and depression scores of immigrants can be predicted based on their levels of acculturation. The weaker the level of acculturation, the higher the chances of facing psychological or mental disorders.

Ismail et al. (2003) conducted a study among international students at IIUM. Students from the Balkans, such as Albanian, Bosnia, Croatia, and Serbia, were called out-group while other students were called in-group. In-group students perceived the Balkans or the out-group students with similar ethnic and cultural backgrounds; they were seen as "Mat Sallah", which in the Malay language means white person but is a term used to refer to Caucasians in general.

Many Balkans students stated that they were perceived as outsiders. The in-group students alienated them due to the prejudice and stereotypes, and labels that emerged from miscommunication and misunderstanding. Therefore, blending, socialising and interacting with locals is fundamental for the immigrants to feel a sense of belonging and assimilate into the host country.

Finally, the Albanian immigrants suggested and recommended. Malaysia is a country that offers many opportunities in terms of education, professional life, business opportunities, and exposure to cultural diversity, which contributes to their emotional growth and help them develop good moral citizenship, thereby benefitting the broader society at large. Several immigrants suggested that practising Islam, Malaysia is a heavenly place because there is no prejudice and discrimination, and every Muslim can practice their beliefs freely.

\section{Implication of the Study}

The findings would be helpful to the university for training purposes, especially health education staff, such as mental health professionals, educational psychologists and policymakers, and other experts in identifying and recognising the psychological health problems amongst immigrants. In particular, they may want to enhance aspects of selfdevelopment, self-actualisation, a sense of belonging and social solid interaction with the community to strengthen the resilience of the immigrants. With this strategy, policymakers and psychologists would be able to improve the mental well-being of immigrants effectively. Ideally, it will make the world a better place for everyone to live in and to hope for and work towards a better future, caring about one another.

For the psychologists and social workers dealing with immigrants, it is recommended that they be alert to the barriers and obstacles faced by the immigrants; it is essential to group immigrants to listen to their concerns. As counsellors, they need to be familiar with all the challenges and act as a moderator to address obstacles faced by immigrants. Psychologists can also conduct a session with all immigrants on the importance of a healthy relationship with immigrants. By doing this, psychologists would be able to create positive interactions between the immigrants. 
It is fundamental for immigrants to do research and get enough information before deciding which country they want to reside, as suggested by the participants. Immigrants are also advised to be open to new experiences in a foreign country so that issues such as new cultures, new people and new food will not be a significant stressor for them. Being a minority group is associated with many challenges regardless of their nationalities and where they are located.

Therefore, it is significant for them to have effective coping strategies to help them deal with and overcome any difficulties facing in the host country. They also must interact and integrate with their country mates and even with locals to assimilate and adjust quickly in a foreign country. Immigrants should seek help no matter what difficulties they face. Voicing out the problem is better than suffocating and suffering in silence as their wellbeing will deteriorate, and they may be more likely to experience some form of psychological distress.

\section{Limitation of the Study}

There are few limitations to this study encountered by the researchers, specifically in generalization and research biases. First, for example, quantitative studies employ numerical data to be more generalized to the entire population. However, qualitative research is more towards understanding and gaining perception towards a specific area of interest. Therefore, purposeful sampling is a more useful device in qualitative research than the use of probability sampling (Merriam, 1998) because it allows the researcher to select the informants to provide rich data, which leads to a limitation that the data collected may be generalized to the entire populations outside of the chosen sample. The generalizability in a qualitative study is too specific to the case studied that it does not generalize to the people. All the participants in this study were not representative of the entire community of Albanian immigrants. Therefore, it needs to consider that this study's results are expected and unique only to the eighteen Albanian informants and do not represent the broader population.

\section{Recommendation for Future Studies}

This study was conducted on the mental well-being of Albanian and Kosovo Albanians immigrants. This study's results can be used as a stepping-stone for further research that will contribute to mental health professionals' knowledge to understand better Albanian immigrants' mental health problems and other immigrants living in Malaysia and Australia. The researchers hope to see papers that address the strategies used to help immigrants overcome difficulties (e.g., mental health problems) and build resilience and studies that endeavour to help immigrants actualize their potential (e.g., positive psychological goals). More qualitative studies are recommended to be conducted on Albanian immigrants' mental well-being living in Malaysia and all other immigrants in general. Different researchers using diverse study approaches will provide a deeper and more significant understanding of the phenomena.

\section{References}

Ahmad, I. S. (2017). Doing qualitative research for beginners: From theory to practice. Partridge Singapore.

Al-Hawdrawi, H. H. (2017). The effect of immigration on the mental well-being of middle eastern immigrants in the united states. Research Journal of Pharmacy \& Technology, 10(7), 2069-2074. https://doi.org/10.5958/0974-360X.2017.00361.4

American Psychological Association. (2016). Guidelines for the undergraduate psychology $\begin{array}{llll}\text { major: } & \text { 2.0. American } & \text { Psychologist, }\end{array}$ 111. https://doi.org/10.1037/a0037562 
Balidemaj, A., \& Small, M. (2018). Acculturation, ethnic identity, and psychological wellbeing of Albanian-American immigrants in the United States. International Journal of Culture \& Mental Health, 11(4), 712-730. https://doi.org/10.1080/17542863.2018.1556717

Bandura, A. (1969). Principle of behaviour modification. Holt, Rinehart \& Winston, Inc.

Banerjee, R., \& Verma, A. (2009). Determinants and Effects of Post-Migration Education Among New Immigrants in Canada. Canadian Labour Market and Skills Researcher Network.

Bezerra, C. I. M., Adriano, A. B. A., Placido, L. S., \& Goncalves, M. G. S. (2010). MiniDMAIC: An approach to causal analysis and resolution in software development projects. In A. Coskun (Ed.), Quality management and six sigma (pp. 155-182). Sciyo. https://www.intechopen.com/books/quality-management-and-six-sigma/minidmaican-approach-to-causal-analysis-and-resolution-in-software-development-projects

Bloch, Maurice (2005) Where did anthropology go?: or the need for 'human nature'. In: Bloch, Maurice, (ed.) Essays on cultural transmission. LSE monographs on social anthropology . Berg Publishers, Oxford, UK, pp. 1-20. ISBN 9781845202866

Bradburn, N. (1969). The structure of psychological well-being. Aldine.

Braun, V., \& Clarke, V. (2006). Using thematic analysis in psychology. Qualitative Research in Psychology, 3(2), 77-101. https://doi.org/10.1191/1478088706qp063oa

Bryman, A. (2008). Social research methods. Oxford University Press.

Bryman, A. (2012). Social research methods (4th ed.). Oxford University Press.

Cela, E., \& Fokkema, T. (2017). Being lonely later in life: A qualitative study among Albanians and Moroccans in Italy. Ageing \& Society, 37(6), 1197-1226. https://doi.org/10.1017/S0144686X16000209

Čiarnienè, R., \& Kumpikaite, V. (2008). The impact of globalization on migration processes. Social Research, 3(13), 42-48. Retrieved from http://talpykla.elaba.lt/elabafedora/objects/elaba:6083070/datastreams/MAIN/content

Coleman, A. M. (2015). Oxford psychology reference dictionary (4th ed.). Oxford University Press.

Cooper, D. R., \& Schindler, P. S. (2003). Business Research Methods (8th edition). USA: McGraw-Hill.

Creswell, J. W. (2007). Qualitative inquiry \& research design, Choosing among five approaches (2nd ed.). Sage.

Dale, B.G., Wiele, T. and Iwaarden, J. (2007) Managing Quality, 5th ed., Blackwell Publishing Ltd., Oxford.

Diener, E. (1984). Subjective well-being. Psychological Bulletin, 95(3), 542-575.

Frisch, M. B. (1998). Quality of life therapy and assessment in health care. Clinical Psychology: Science and Practice, 5(1), 19-40. https://doi.org/10.1111/j.1468-2850.1998.tb00132.x

Fyodor, D. (1912). The novels of Fyodor Dostoevsky (C Garnett, Trans.). William Heinemann.

Harrison, D. A., \& Klein, K. J. (2007). What's the difference? Diversity constructs as separation, variety, or disparity in organizations. Academy of Management Review, 32(4), 1199-1228. https://doi.org/10.5465/AMR.2007.26586096

Hemmasi, M., \& Downes, M. (2013). Cultural distance and expatriate adjustment revisited. Journal of Global Mobility: The Home of Expatriate Management Research, 1, 72-91.

Hesse, Hermann. Herman Hesse Steppenwolf. New York: Holt, Rinehart and Winston, 1961. Print.

Hinsliff, J. (2007). Integration or exclusion? The resettlement experiences of refugees in Australia. University of Adelaide.

Husserl E (2004) Ideas : General Introduction to Pure Phenomenology, Taylor and Francis, Florence. 
Ismail, N. A. H., Rahman, N. S. N. A., Nordin, M. S. N., \& Zainuddin, A. M. H. (2003). Integration and internalization in the inter-group relations in institutions of tertiarry education: A case study of the International Islamic University Malaysia. Muslim Education Quarterly, 20(1 \&2), 52-66. http://irep.iium.edu.my/26333/

Kabir, S. M. (2013). Positive attitude can change life. Journal of Chittagong University Teachers' Association, 7, 55-63. https://www.researchgate.net/publication/325712867_Positive_Attitude_Can_ Change_Life

Kahanec, M., \& Zimmermann, K. F. (2008). Migration and globalization: Challenges and perspectives for the research infrastructure (IZA Discussion Paper No. 3890). SSRN Electronic Journal. https://papers.ssrn.com/sol3/papers.cfm?abstract_id=1318849

Kaliska, L., \& Akbey, B. (2019). Post-traumatic Stress Disorder Related to Trait Emotional Intelligence of Slovaks in Comparison to Turkish Immigrants in Slovakia. Journal of Ethnic and Cultural Studies, 6(3), 147-157.

Kasimati, M., Kolpeja, V., \& Habiti, D. (2009). Migracionic Shqiptar pas viteve 90 dhe ndikimi I tij ne jeten ekonomike dhe sociale te femijeve te lene pas. Insituti per Kerkime Urbane. http://www.uri.org.al/uri/pub/raporti_shqip3.pdf

Kim, B. S. K. (2006). Acculturation and enculturation. In F. T. L. Leong, A. Ebreo, \& L. Kinoshita (Eds.), Handbook of Asian American psychology (2nd ed., pp. 141-158). Sage Publications.

Locke, E. A., \& Latham, G. P. (2019). The development of goal-setting theory: A half-century retrospective. Motivation Science.

Lunenburg, F. C. (2011). Self-Efficacy, Adaptation, and Adjustment. International Journal Of Management, Business, And Administration, 14(1), 1-6.

Madani, A. H. (2011). Freedom and Its Concept in Islam. International Proceedings of Economics Development \& Research, 17, 116. http://www.ipedr.com/vol17/21-CHHSS 2011-H10000.pdf

McKnight, P. E., \& Kashdan, T. B. (2009). Purpose in life as a system that creates and sustains health and well-being: An integrative, testable theory. Review of General Psychology, 13(3), 242-251. https://doi.org/10.1037/a0017152

Merriam, S. B. (2009). Qualitative research: A guide to design and implementation. JosseyBass.

Merriam, S.B. (1998) Qualitative Research and Case Study Applications in Education. JosseyBass Publishers, San Francisco.

Migration, W. (2018). Chapter 2 - Migration and migrants: A global overview. World Migration Report (Vol. 2018). https://doi.org/10.1002/wom3.2

Papadopoulos, D. K., Karasavvoglou, A., Geranis, C., \& Violitzi, K. (2015). The effect of socio-demographic variables on acculturation of Albanian immigrants in Greece. Procedia Economics \& Finance, 19(15), 154-166. https://doi.org/10.1016/s22125671(15)00017-9

Patton, M. Q. (1990). Qualitative evaluation and research methods (2nd ed.). Sage Publications.

Phua, J. J. (2010). Sports Fans and Media Use: Influence on Sports Fan Identification and Collective Self-Esteem. International Journal of Sport Communication, 3(2), 190-206. https://doi.org/10.1123/ijsc.3.2.190

Pope, C., Mays, N., \& Popay, J. (2007). Synthesizing qualitative and quantitative health research. Open University Press.

Pringle, J., Drummond, J., McLafferty, E., \& Hendry, C. (2011). Interpretative phenomenological analysis: a discussion and critique. Nurse researcher, 18(3), 20-24. https://doi.org/10.7748/nr2011.04.18.3.20.c8459

Ryan, R. M., \& Deci, E. L. (2001). On happiness and human potentials: A review of research on hedonic and eudaimonic well-being. Annual review of psychology, 52(1), 141-166. 
Ryff, C. D. (1989). Happiness is everything, or is it? Explorations on the meaning of psychological well-being. Journal of Personality \& Social Psychology, 57(6), 10691081. https://doi.org/10.1037/0022-3514.57.6.1069

Ryff, C. D., \& Keyes, C. L. M. (1995). The structure of psychological well-being revisited. Journal of Personality \& Social Psychology, 69(4), 719727. https://doi.org/10.1037/0022-3514.69.4.719

Ryff, C. D., \& Singer, B. H. (2008). Know thyself and become what you are: A eudemonic approach to psychological well-being. Journal of Happiness Studies, 9, 13-39.

Shah, A. A. (2005). Psychotherapy in vacuum or reality: Secular or Islamic psychotherapy with Muslim clients! Pakistan Journal of Social and Clinical Psychology, 3, 1-18.

Shah, D. A. H., \& Sani Mohd, M. A. (2011). Freedom of Religion in Malaysia: A Tangled Web of Legal, Political, and Social Issues. North Carolina Journal of International Law and Commercial Regulation (Vol. 36).

Tribe, R. (2002). The mental health of refugees and asylum seekers. Advances in Psychiatric Treatment, 8, 240-247.

Tssari, H. (2018). Calmness conquers anxiety: What language tells us about mind and body control. In H. Çakmur (Ed.), Effects of stress on human health (pp. 565-474). Intechopen. $\quad$ https://www.intechopen.com/books/effects-of-stress-on-humanhealth/calmness-conquers-anxiety-what-language-tells-us-about-mind-and-bodycontrol

Walter, O., \& Siwar, S. (2021). Personal Well-Being, Mental Resilience and Emotional Intelligence in First-and Second-Generation Druze in the Golan Heights. Journal of Ethnic and Cultural Studies, 8(3), 74-94.

Wang, H. T., Chang, W., \& Lai, Y. F. (2012). a Study on the relationship between thinking styles (attitudes) and collaboration attitudes of college students in Taiwan. Journal of Education \& Instructional Studies, 2(2), 46-57.

WHO (1948). Constitution of the World Health Organization. Basic documents. Geneva, World Health Organization.

Wong, D. F. K. (2002). Stage-specific and culture-specific coping strategies used by mainland Chinese immigrants during resettlement in Hong Kong. Social Work in Health Care, 35(1-2), 479-499. https://doi.org/10.1300/J010v35n01_08

\section{Notes on Contributors}

Dr. Nik Ahmad Hisham is a Professor at the Department of Educational Psychology and Counseling. He has served as Dean of Kulliyyah of Education, and he was assigned as the Director of the Institute of Education, IIUM, in 2008. He is specialized in Social Science, Education, Educational Psychology. His teaching and research interests are in mental health, mental health in school, social psychology in education, and personality and personality disorder theories.

Voltisa Thartori, received her $\mathrm{PhD}$ in Educational Psychology at International Islamic University Malaysia in March, 2021. She is specialized in Education, Educational Psychology. Her research interest consists of mental health and mental wellbeing, education, educational psychology, and social science. 